\title{
LER E ESCREVER NA UNIVERSIDADE: UM FAZER SÓCIO-HISTÓRICO-CULTURAL
}

\author{
Rodrigo Acosta Pereira* \\ Sandro Braga* \\ Universidade Federal de Santa Catarina \\ Centro de Comunicação e Expressão \\ Departamento de Língua e Literatura Vernáculas \\ Florianópolis, SC, Brasil
}

\begin{abstract}
Resumo: O presente artigo objetiva delinear uma discussão teórico-metodológica acerca das práticas de ensino e de aprendizagem da leitura e da escrita na esfera acadêmica à luz das considerações epistemológicas de cunho sócio-histórico. Para tanto, revisitamos os escritos do Círculo de Bakhtin, assim como as postulações dos Novos Estudos de Letramento, a fim de construir inteligibilidades em torno das práticas de uso da língua escrita na universidade. Acreditamos que o trabalho apresenta-se relevante não apenas porque, a nosso ver, procura contribuir com as discussões atuais da Linguística Aplicada sobre as práticas de escrita e leitura na academia, como, por conseguinte, corrobora as contribuições dos estudos bakhtinianos e as pesquisas sobre letramento acadêmico para a ressignificação do fazer pedagógico em torno do ensino e da aprendizagem da leitura e da escrita na universidade.
\end{abstract}

Palavras-chave: Leitura. Escrita. Esfera acadêmica. Gênero do discurso. Letramento(s).

\section{INTRODUÇÃO}

Este ensaio caracteriza-se enquanto um diálogo engendrado a partir de elos autorais com vozes $^{1}$ outras, não apenas auscultando-as, mas, sobretudo, reacentuandoas, buscando nessa ação dia-lógica (PONZIO, 2012), na escuta do outrem, coconstruir integibilidades sobre as práticas de leitura e escrita na universidade.

Nosso diálogo consocia-se, sob essa perspectiva, a duas posições: a concepção dialógica da linguagem a partir dos escritos do Círculo de Bakhtin, pois entendemos que lemos e escrevemos textos-enunciados, isto é, unidades concretas da comunicação verbal (BAKHTIN, 2003[1979]); e a dos Estudos de Letramento, na medida em que compreendemos que ler e escrever são práticas sociais e, portanto, consubstanciadas por conjecturas de ordem histórica e cultural (BARTON, 2004). Iniciamos abordando

\footnotetext{
* Professor de Linguística Aplicada no Programa de Pós-graduação em Linguística e no Programa de Mestrado Profissional em Letras (PROFLETRAS). Email: drigo_acosta@yahoo.com.br.

** Professor de Linguística Aplicada no Programa de Pós-graduação em Linguística. Email: sandrocombraga@gmail.com.

${ }^{1}$ Entendemos voz, sob o matiz bakhtiniano, como uma posição semântico-axiológica de dizer sobre e para o mundo.
} 
aspectos conceituais voltados aos escritos do Círculo de Bakhtin, em especial, acerca das concepções de enunciado e gênero do discurso, assim como retomando, sempre que necessário, as demais orientações teórico-epistemológicas e metodológicas do Círculo, e, em um segundo momento, (re)enunciamos as diversas posições dos Estudos de Letramento, voltadas à compreensão da leitura e da escrita sob um matiz ideológico e crítico.

\section{LER E ESCREVER TEXTOS-ENUNCIADOS: ASPECTOS CONCEITUAIS EM TORNO DOS ESCRITOS DO CÍRCULO DE BAKHTIN}

Em Linguística, sob um recorte ilustrativo (grosso modo), diferentes áreas têm trazido à tona o conceito de enunciado, seja sob um ponto de vista linguístico-estrutural (BENVENISTE, 1966), semântico-argumentativo (DUCROT, 1987), seja linguísticotextual (ADAM, 1990; 1992), por exemplo. Nesta discussão, referimo-nos à visão de enunciado enquanto unidade concreta de sentido do uso da língua em situações de interação. Em outras palavras, nossa posição é endereçada nos escritos do Círculo de Bakhtin, a partir dos quais o enunciado ${ }^{2}$ é visto como um "[...] fenômeno ideológico, concreto, que é sempre material e histórico.” (MEDVIÉDEV, 2012[1928], p. 44). Assim, não estaremos vinculando o enunciado a construções linguístico-estruturais de ordem argumentativa ligadas ao contexto de uso em oposição à frase, ou à configuração pragmática de proposições, mas estaremos compreendendo, em todos os momentos desta discussão, que o enunciado diz respeito a "[...] um sentido concreto [...] uma realidade concreta em condições igualmente reais de comunicação discursiva." (BAKHTIN, 2003[1979], p. 291).

Inicialmente, podemos entender que, para o Círculo, todo enunciado é integrado à situação de interação, ou seja, a situação de enunciação (a dimensão extraverbal) não é um elemento externo ao enunciado, mas o engendra. Assim, toda situação de interação envolve o enunciado, consubstanciando-o, dotando-o de sentido. Em outras palavras, "qualquer enunciado é orientado [...] para uma determinada forma de comunicação social [...]. A comunicação, nesse sentido geral, é um aspecto construtivo da língua como tal.” (MEDVIÉDEV, 2012[1928], p. 152-153). Na voz do autor,

\footnotetext{
Qualquer enunciado concreto é um ato social. Por ser também um conjunto material peculiar - sonoro, pronunciado, visual -, o enunciado ao mesmo tempo é uma parte da realidade social. Ele organiza a comunicação que é voltada para uma reação resposta, ele mesmo reage a algo; ele é inseparável do acontecimento da comunicação. Sua realidade peculiar enquanto elemento isolado já não é a realidade de um corpo físico, mas a de um fenômeno histórico. (MEDVIÉDEV, 2012[1928], p. 183).
}

Com isso, ao lermos e escrevermos textos-enunciados na universidade estamos, sobretudo, nos situando em uma dada circunstância, em dado momento histórico, nas

\footnotetext{
2 Entendemos enunciado, texto-enunciado, palavra-enunciado, fenômeno-enunciado como termos equivalentes nesta discussão, dado o fluxo terminológico recorrente nos escritos do Círculo.
} 
condições de dada situação social. Se publicar um artigo científico ${ }^{3}$ parece ser uma prática recorrente e mais usual na área de Física em relação à publicação de livros na área de Letras, por exemplo, é porque, dadas as circunstâncias histórico-culturais, ideológicas e valorativas, o artigo científico, na área de Física, parece ser o recurso no qual pesquisadores desse campo têm valorado enquanto modo frequente de produção e divulgação de estudos recentes (MOTTA-ROTH; HENDGES, 2010), enquanto, na área de Letras, é a publicação de livros, práticas, portanto, singulares de uso da língua. Ao escrever uma resenha de um livro recém- publicado, apresentando à comunidade acadêmica uma determinada avaliação deste, estamos nos circunscrevendo a uma dada situação social, cujas conjecturas nessa situação (contexto histórico-cultural, valorativo e ideológico, autoria, público-leitor em potencial) engendram-se em nosso enunciado resenha, reunindo a presença material da palavra com o seu sentido ${ }^{4}$ (agenciamento de recursos linguístico-textuais e enunciativos à luz das condições da situação social).

Como já dito, o enunciado é um acontecimento da história e "sua peculiaridade é a peculiaridade de uma realização histórica em determinada época e com determinadas condições sociais." (MEDVIÉDEV, 2012[1928], p. 183-184) e os recursos linguísticos que se operam no enunciado seguem essas determinações. A partir disso, podemos compreender que todo enunciado está integrado à situação de comunicação e a construção do enunciado não se refere ao arranjo de elementos linguísticos de forma intrassistêmica, mas, de fato, às condições e objetivos da situação de comunicação.

Assim, após entendermos a situação social como um elemento constitutivo do enunciado, dando-lhe "o relativo acabamento" (ACOSTA-PEREIRA, 2008; 2012; RODRIGUES, 2005), cabe discutirmos, em adição, as peculiaridades ou características distintivas do enunciado, diferenciando-os da oração, unidade da língua, questões que contribuem para nossa busca de entendimento do que seja o enunciado enquanto unidade concreta da comunicação verbal.

Bakhtin (2003[1979]) apresenta como características distintivas dos enunciados: (i) a alternância dos sujeitos do discurso; (ii) a conclusibilidade e (iii) a expressividade. Para o Círculo, por mais distintos que sejam os textos-enunciados em função de sua extensão, estilo ou composição (veja uma resenha em relação a uma tese de doutorado), todo enunciado possui peculiaridades comuns e "[...] antes de tudo limites absolutamente precisos." (p. 274-275, grifo do autor). Uma das peculiaridades diz respeito à alternância dos sujeitos do discurso, isto é, como bem reitera o autor, a alternância dos falantes do enunciado. Com formas diversas e sob o matiz de propósitos plurais, a alternância dos falantes do enunciado define, de forma relativamente acabada, o início e o fim do enunciado, seu dixi conclusivo. A alternância cria limites precisos para o enunciado e "[...] termina com a transmissão da palavra ao outro [...]." (BAKHTIN, 2003[1979], p. 275).

A alternância ocorre, como já dito, de formas diversas, podendo ser momentânea como nos exemplos acima ou retardada, como nas respostas que emitimos aos diversos

\footnotetext{
${ }^{3}$ Marcaremos em itálico toda vez que nos remetermos a gêneros da esfera acadêmica.

4 "Por meio da avaliação de novas publicações, o conhecimento na disciplina [...] se reorganiza e as relações de poder, de status acadêmico se reacomodam.” (MOTTA-ROTH; HENDGES, 2010, p. 27).
} 
textos-enunciados que lemos ou que escrevemos. Ao lermos um capitulo de um livro e logo depois emitirmos uma avaliação responsiva (concordância, discordância, aceitação, recusa etc.) ou ao escrevermos um resumo em volta desse mesmo capítulo, estamos nos circunscrevendo em situações sociais nas quais alternamos a posição de sujeitos com o sujeito-autor desses textos-enunciados.

Como explica Bakhtin (2003[1979], p. 275-276), “cada réplica, por mais breve e fragmentária que seja, possui uma conclusibilidade específica ao exprimir certa posição do falante que suscita resposta, em relação à qual se pode assumir uma posição responsiva." Ainda, reitera o autor, "essas relações só são possíveis entre enunciações de diferentes sujeitos do discurso [...]." Assim, com base nessas considerações, podemos entender que o que caracteriza o enunciado, dentre outras peculiaridades, é a possibilidade que este agencia de todo sujeito do discurso ocupar uma posição responsiva. Em outras palavras, todo enunciado demanda respostas e essas advêm da relação intersubjetiva que se constrói em dada situação mediada pelo enunciado. $\mathrm{O}$ enunciado sempre mantém relação imediata com enunciados outros e possui capacidade de determinar a posição de resposta do outro a partir da alternância que se estabelece na enunciação.

Dessa caracterização, o autor nos conduz à segunda peculiaridade do enunciado, a conclusibilidade. Para o autor, a conclusibilidade é "uma espécie de aspecto interno da alternância dos sujeitos do discurso." (BAKHTIN, 2003[1979], p. 280). Ainda, essa peculiaridade é específica e determinada por categorias que conferem relativo acabamento ao enunciado: a exauribilidade semântico-objetal do tema; a vontade discursiva do falante e as formas estáveis do gênero. Para fins de explicitação, propomos um quadro explicativo com base nas colocações do autor:

\section{Quadro 1 - Peculiaridades do enunciado}

\begin{tabular}{|l|l|}
\hline Exauribilidade semântico-objetal do enunciado & $\begin{array}{l}\text { É a exauribilidade do objeto e do sentido, isto é, o que } \\
\text { pode ser discursivizado em dada situação social e no } \\
\text { âmbito de uma ideia visada pelo autor. }\end{array}$ \\
\hline Intenção ou vontade discursiva do falante & $\begin{array}{l}\text { "É o que determina o todo do enunciado, o seu volume e } \\
\text { as suas fronteiras. Imaginamos o que o falante quer } \\
\text { dizer, e com essa ideia verbalizada, essa vontade } \\
\text { verbalizada [...] é que medimos a conclusibilidade do } \\
\text { enunciado." (BAKHTIN, 2003[1979], p. 281). }\end{array}$ \\
\hline As formas estáveis de gênero do enunciado & $\begin{array}{l}\text { "Formas relativamente estáveis e típicas da construção } \\
\text { do todo." (BAKHTIN, 2003[1979], p. 282, grifos do } \\
\text { autor). }\end{array}$ \\
\hline
\end{tabular}

Fonte: Bakhtin (2003 [1979]).

Como podemos perceber, a exauribilidade semântico-objetal diz respeito ao que está sendo discursivizado no enunciado em dada situação de interação, ou seja, o objeto a ser tematizado, seguindo a vontade discursiva do falante. Esta, por sua vez, corresponde ao projeto de discurso do sujeito, sua intenção, seu querer-dizer. Desse querer-dizer não apenas ascende $o$ que se pode dizer, como, por conseguinte, o como se pode dizer, a forma típica do enunciado, seu gênero de discurso (questão a ser abordada 
a seguir). Por exemplo, ao ler um trabalho de conclusão de curso (TCC) ou uma tese de doutorado, antes de tudo atentamos para o objeto a ser tratado nesses textos-enunciados, nos perguntando, geralmente, sobre do que se trata; o que o pesquisador investigou; sobre como a pesquisa foi realizada. Dadas as circunstâncias de um TCC ou de uma tese, o objeto é tratado de forma diferente, seja em torno da extensão, do volume, do estilo, seja em volta da composição e da própria situação de interação que se estabelece.

Compreendemos, assim, que todo enunciado atinge relativo grau de conclusibilidade, permitindo suscitar respostas. Esse trabalho é determinado, portanto, pelos três elementos ligados ao todo orgânico do enunciado, conferindo-lhe sentido e conclusividade: o tratamento exaurível do objeto e do sentido; o projeto de discurso do sujeito-autor e as formas estilístico-composicionais do gênero do enunciado.

Em relação à expressividade, Bakhtin (2003[1979]) explica-nos que corresponde à relação do enunciando com o próprio sujeito-autor e com os demais interlocutores da situação social, ou seja, "a relação subjetiva emocionalmente valorativa do falante com o conteúdo do objeto e do sentido do enunciado." (p. 289). A expressividade, além de corresponder à projeção axiológica do enunciado e, portanto, ao valor que o sujeitoautor imprime à situação, diz respeito, em adição, à escolha dos recursos linguísticogramaticais e textuais que o sujeito-autor agencia em seu enunciado para tal.

Para o Círculo, "as palavras não são de ninguém, em si mesmas nada valorizam, mas podem abastecer qualquer falante e os juízos de valor mais diversos e diametralmente opostos dos falantes" (BAKHTIN, 2003[1979]) p. 290). A expressividade, com isso, é o que impossibilita o enunciado de ser neutro, pois é o contato da língua com a realidade que gera a centelha da expressão. "Portanto, a emoção, o juízo de valor, a expressão são estranhos à palavra da língua e surgem unicamente no processo de seu emprego vivo em um enunciado concreto." (BAKHTIN, 2003[1979], p. 292).

Quando assistimos a uma palestra, o palestrante pode imprimir em seu discurso determinados tons expressivos. Pode se posicionar contrário a um determinado campo científico, desqualificando-o, como, por outro lado, pode colocar-se numa posição de "moderador", dialogando com dois horizontes epistemológicos divergentes. Nos dois casos, sua palestra, enquanto texto-enunciado, se construirá em uma dada projeção expressiva, valorativa, agenciando determinados recursos linguísticos (gramaticais, textuais, multissemióticos) para ratificar essa projeção.

Em um ensaio acadêmico, podemos discutir um conceito sob o horizonte apreciativo de uma dada teoria $\mathrm{X}$ ou $\mathrm{Y}$, isto é, o ensaio será construído a partir do ponto de vista expressivo que imprimirmos sob dado objeto. Assim, nossos enunciados recebem o matiz da expressão valorativa determinada pelo projeto discursivo do sujeitoautor, que não apenas recorta o objeto tematizado de forma singular como agencia recursos linguísticos a favor desse matiz. Para Bakhtin (2003[1979], p. 298-299, (grifo nosso), "a expressão do enunciado, em maior ou menor grau, responde, isto é, exprime a relação do falante com os enunciados do outro, [...] é pleno de tonalidades dialógicas." Sob a perspectiva da palestra, ao nos posicionarmos contrários a determinado campo científico, procurando apresentar subsídios ao outro dessa discordância, reenunciamos dizeres de outrem, que possam, na situação social dada, convergir com nosso dizer. 
Então, tudo sobre o que falamos nunca é a primeira vez dizível à situação, mas sempre está envolto nos dizeres outros sobre ele. Em outras palavras, “o enunciado é um elo na cadeia da comunicação discursiva e não pode ser separado dos elos precedentes que o determinam tanto de fora quanto de dentro, gerando nele atitudes responsivas diretas e ressonâncias dialógicas." (BAKHTIN, 2003[1979], p. 300).

Ao entrar em relação dialógica com o enunciado do outro, imprimindo a expressividade intencional na dada situação, todo sujeito-autor tem em vista seu interlocutor. Cada enunciado tem um interlocutor e o sujeito-autor constrói seu enunciado tendo em vista este (seja em torno do que se fala, seja da expressão valorativa que se imprime). Assim, se estamos em uma palestra para alunos de graduação, a apresentação poderá estar diferente de uma palestra para professores doutores pesquisadores da área que se aborda. Com isso, Bakhtin explica que, como todo enunciado, e suas formas típicas - os gêneros -, têm uma concepção de autor e de destinatário; ao enunciar, todo sujeito-autor leva sempre em consideração seu público em potencial, seu fundo aperceptivo (até que ponto o outro conseguirá compreendê-lo?). Não poderíamos apresentar um determinado estudo com alto grau de complexidade para um público que não compartilha conosco de conhecimentos prévios sobre dado tema, por exemplo.

A partir disso, a terceira peculiaridade do enunciado corrobora a acepção de que todo enunciado é valorativo, expressivo, axiológico. E esse valor que colore todo enunciado sempre é correlacionado ao matiz da situação social, seja da posição que assume o sujeito-autor, seja do fundo aperceptivo de seu interlocutor.

Dada a discussão em volta das peculiaridades dos enunciados e visto que todo enunciado relativamente estável apresenta formas típicas - os gêneros -, direcionemos nossa discussão para o conceito de gêneros do discurso. Embora não tenhamos delineado até este momento questões específicas em torno do gênero, suas particularidades estão imbricadas às particularidades do enunciado. Além disso, a todo momento, nesta discussão, as exemplificações giraram em torno de gêneros do discurso da esfera acadêmica, como podemos visualizar na retomada dos gêneros no quadro a seguir:

\section{Quadro 2 - Alguns gêneros da esfera acadêmica}

\begin{tabular}{|c|}
\hline Palestra \\
\hline Artigo \\
\hline Resenha \\
\hline Resumo \\
\hline
\end{tabular}

Fonte: Discussão dos autores.

Para o Círculo, nós nos utilizamos da língua na forma de enunciados. E os enunciados, quando tipificados nas diversas situações de interação, relativamente se estabilizam na forma de gêneros do discurso. Portanto, são os gêneros que orientam o 
sujeito-autor no processo de comunicação e o interlocutor no relativo acabamento do enunciado. Assim, para Bakhtin (2003[1979]), por mais diferentes que sejam os enunciados, estes, como unidades da comunicação discursiva, possuem características comuns e lhes dão acabamento, como vimos, dentre essas, as formas típicas de gênero.

Como explicam Acosta-Pereira (2012) e Rodrigues (2005), os gêneros do discurso podem, em relação ao sujeito-autor (falante), ser considerados como modelos relativamente estáveis para a construção do todo do enunciado; por outro lado, em relação ao interlocutor (o ouvinte), os gêneros do discurso se apresentam como certos "horizontes de expectativas", sinalizando ao outro sua extensão, sua composição, sua posição expressiva, possibilitando, por exemplo, a alternância na comunicação. Quando lemos uma resenha, por exemplo, sabemos que, geralmente, a recomendação ou não da obra apresenta-se ao final, após a avaliação. A análise dos dados e a conclusão em um artigo científico são partes finais desse gênero. Ao ler uma resenha ou um artigo científico, como nos exemplos acima, o ouvinte (o leitor), desde o início, infere o gênero no qual o enunciado se encontra moldado e, dessa forma, as feições do gênero em questão já se constituem como elementos indispensáveis à compreensão (interpretação) desses enunciados.

[...] a enunciação é produto da interação de dois indivíduos socialmente organizados [...]. A palavra dirige-se a um interlocutor [...]. Na realidade, toda a palavra comporta duas faces. Ela é determinada tanto pelo fato de que procede de alguém, como pelo fato de que se dirige para alguém. Ela constitui justamente o produto da interação do locutor e do ouvinte. Toda palavra serve de expressão a um em relação ao outro. [...] A palavra é uma espécie de ponte lançada entre mim e os outros. Se ela apoia em mim numa extremidade, na outra se apoia sobre o meu interlocutor. A palavra é um território comum do locutor e do interlocutor. (BAKHTIN [VOLOCHÍNOV], 2006[1929], p. 117, grifo dos autores).

Podemos, assim, compreender que qualquer que seja o enunciado, ele é determinado pelas condições reais da situação de comunicação em questão, como vimos no início deste ensaio. A situação social imediata e o meio social mais amplo, em seus matizes históricos, culturais, ideológicos e valorativos determinam o gênero. Os gêneros não são criados pelos seus falantes, mas lhes são dados historicamente, e o uso de um determinado gênero e outro está consociado a sua esfera de atividade humana, historicamente definida (BAKHTIN, 2003[1979]).

Bakhtin (2003[1979]) propõe as esferas sociais como princípio organizador dos gêneros. As esferas tipificam situações de interação, estabilizando relativamente os enunciados que nelas circulam, originando gêneros do discurso particulares dessas esferas. $\mathrm{Na}$ universidade, nossas práticas de uso da língua (escrita, oral, multissemiótica) são relativamente estabilizadas pelo campo no qual os enunciados são produzidos e circulam, a própria esfera acadêmica. Determinados gêneros são particulares desse campo, não mediando situações de interação em esferas outras. Como explica Medviédev (2012[1928], p. 198), "se abordarmos o gênero do ponto de vista da sua relação interna e temática com a realidade e sua formação, então, podemos dizer que cada gênero possui seus próprios meios de visão e de compreensão da realidade, que são acessíveis somente a ele." A partir disso, escrever resumo indicativo ou relatório de um projeto de pesquisa parece ser práticas típicas e relativamente estáveis de uso da língua 
na esfera acadêmica. E os gêneros, que medeiam essas práticas, servem para orientar e discursivizar certos aspectos da realidade acessíveis a eles: realizar uma inscrição em um evento científico e relatar as ações de um projeto de iniciação científica, por exemplo. Desse modo, "cada gênero é capaz de dominar somente determinados aspectos da realidade, ele possui certos princípios de seleção, determinadas formas de visão e de compreensão dessa realidade [...]." (MEDVIÉDEV, 2012[1928], p. 196). Cada gênero, em síntese, é um complexo arranjo de meio de acabamento do real.

Além disso, cada esfera conhece e aplica os seus próprios gêneros (RODRIGUES, 2005), posto que as características particulares da constituição e do funcionamento dos gêneros estão vinculadas às especificidades das esferas nas quais estes funcionam, circulam e significam (ACOSTA-PEREIRA, 2012). Cada esfera, portanto, organiza suas formas típicas de comunicação social, e um exemplo, por assim dizer, pode ser as várias formas de resenhar e de resumir nas diversas esferas. Os gêneros se constituem a partir de situações da vida social relativamente estáveis, ou seja, imersos nas esferas sociais que, por sua vez, comportam diversos intercâmbios comunicativos.

\begin{abstract}
Desse modo, a realidade do gênero e a realidade que o gênero pode alcançar estão organicamente ligadas. Porém, vimos que a realidade do gênero é a realidade social de sua realização no processo de comunicação social. Dessa forma, o gênero é um conjunto de meios de orientação coletiva na realidade, dirigido para seu acabamento. Essa orientação é capaz de compreender novos aspectos da realidade. A compreensão da realidade desenvolve-se e origina-se no processo de comunicação social ideológica. (MEDVIÉDEV, 2012[1928], p. 200).
\end{abstract}

Como podemos compreender na voz de Medviédev (2012[1928]), em função da complexidade de cada esfera e da pluralidade de orientações para o real, a diversidade e a fluidez dos gêneros são infinitas. Conforme Bakhtin (2003[1979]) explica, são inesgotáveis as possibilidades das ações humanas, e como cada esfera dessas atividades se organiza originando gêneros particulares, há sempre a possibilidade do surgimento de novos gêneros. Ademais, como os gêneros são fluidos e dinâmicos, podem se modificar com o tempo e em função das situações de interação que se modificam. Um fichamento de um livro em cartões, hoje, em pleno século XXI, parece não ser mais usual, dados os múltiplos recursos tecnológicos para produzir um fichamento em ambiente virtual, por exemplo.

Os gêneros refletem as tendências mais perenes da evolução histórica (BAKHTIN, 2008[1963]). Entretanto, todo gênero, mesmo no processo de atualização e de renovação, conserva as particularidades características de tempos anteriores: mesmo sendo um fichamento em ambiente virtual, certas feições estilístico-composicionais (as mais "peculiares") do gênero fichamento em cartões se mantêm, por exemplo. Para Bakhtin (2008[1963], p. 121),

\footnotetext{
O gênero conserva sempre os elementos imorredouros da archaica. É verdade que nele essa archaica só se conserva graças a sua permanente renovação, vale dizer graças a sua atualização. O gênero sempre é e não é ao mesmo, sempre é novo e velho ao mesmo tempo. O gênero renasce e se renova em cada etapa do desenvolvimento [...] em cada obra individual de um dado gênero. Nisto consiste a vida do gênero. Por isso, não é morta nem a
} 
archaica que se conserva no gênero; ela é eternamente viva, ou seja, é uma archaica com capacidade de renovar-se. O gênero vive do presente, mas sempre recorda o seu passado, o seu começo. (BAKHTIN, 2008[1963], p. 121, grifos do autor).

Todo gênero do discurso possui uma lógica concreta orgânica (como já dito, no início do ensaio) determinada criativamente a partir de protótipos ou fragmentos do gênero. Assim, cada variedade do gênero, ou cada novo gênero, sempre generaliza essa lógica, contribuindo para sua renovação. Além disso, podemos entender que novos gêneros nascem como resultado de mudanças sociais, a partir do advento de novas práticas sociais e, por conseguinte, de novas práticas de uso da linguagem. Atualmente, por exemplo, tornou-se habitual, em diversos eventos científicos, a inscrição mediante um resumo expandido, diferentemente do resumo indicativo de até 250 ou 300 palavras. Um outro exemplo seria o caderno de handouts, recurso utilizado na comunicação oral como suporte para registro das ideias explicitadas somente na oralidade e que tem se tornado recorrente em diversos eventos. Utilizar-se de um resumo mais longo e detalhado de dada pesquisa para inscrição em um evento e reunir handouts das apresentações caracterizam novas práticas sociais de uso da linguagem, agenciando gêneros para tanto.

Sob essa perspectiva, podemos compreender que as formas de interação verbal, sensíveis a todas as transformações sociais, acham-se estreitamente vinculadas às condições da situação de interlocução dada e reagem sensivelmente a todas as flutuações da atmosfera social. Novos usos da linguagem em situações sociais potencializam o uso de novas formas de uso da língua, novos gêneros do discurso. Assim, todo gênero não apenas responde às necessidades sociais e às experiências intersubjetivas, como também, por conseguinte, traz em si uma apreciação da realidade social (MEDVIÉDEV, 2012[1928]).

Outra questão importante é entender que os gêneros do discurso são formas de organização de nosso discurso, permitindo a comunicação social inteligível. Imaginemos se, ao escrever uma dissertação de mestrado, cada um seguisse um modo específico de escrita à luz da criatividade subjetiva. Mesmo sendo plásticos e fluidos, os gêneros são enunciados estáveis, organizando nosso discurso, refletindo as condições específicas e as finalidades de cada esfera social por meio da relativa estabilidade (regularidade) do objeto temático, como também do estilo e da orquestração composicional. As instâncias estão indissoluvelmente ligadas no todo do enunciado e são igualmente determinadas pela especificidade da esfera. Para fins didáticos, vejamos no quadro 3, a seguir, as instâncias constitutivas dos gêneros do discurso, com base na pesquisa de Acosta-Pereira (2012).

Com efeito, em todo gênero agenciam-se conteúdo temático, estilo e composição, que, num trabalho conjunto, imprimem relativa estabilidade a este. Como os gêneros orientam-se na e para a vida, refletindo e refratando determinados aspectos da realidade, as instâncias constitutivas trabalham nesses dois planos. Em suma, podemos entender que todo enunciado típico se materializa em um gênero e este, por sua vez, agencia conteúdo temático, estilo e composição conforme as especificidades da esfera e das condições sociais da situação de interação que medeia. Os gêneros podem ser considerados formas sociais de ver e interpretar aspectos particulares do mundo, pois, enquanto sujeitos sociais, experenciamos o mundo por meio de gêneros do discurso. 
Quadro 3 - Instâncias constitutivas dos gêneros do discurso

\begin{tabular}{|l|l|}
\hline Conteúdo temático & $\begin{array}{l}\text { Todo gênero tem um conteúdo temático, seu } \\
\text { objeto de discurso, sua unidade de sentido e uma } \\
\text { orientação ideológica específica. Não é o assunto } \\
\text { específico do gênero, mas o domínio de sentido de } \\
\text { que se ocupa o gênero. Desse modo, podemos } \\
\text { compreender que o conteúdo temático diz respeito } \\
\text { à maneira como o gênero seleciona elementos da } \\
\text { realidade e como os trata na constituição de seu } \\
\text { objeto de discurso. }\end{array}$ \\
\hline Estilo & $\begin{array}{l}\text { Seleção típica de recursos lexicais, fraseológicos e } \\
\text { gramaticais da língua. Diz respeito às } \\
\text { possibilidades de utilização de recursos } \\
\text { linguísticos agenciados por um gênero. }\end{array}$ \\
\hline Orquestração composicional & $\begin{array}{l}\text { Procedimentos de disposição, orquestração e } \\
\text { acabamento do enunciado, eleva em consideração } \\
\text { a mobilização dos participantes da comunicação. É } \\
\text { responsável pela organização material do } \\
\text { enunciado. É uma forma padrão relativamente } \\
\text { estável. }\end{array}$ \\
\hline
\end{tabular}

Fonte: Bakhtin (2003 [1979]).

Em nossa discussão em torno do enunciado e do gênero do discurso, procuramos delinear caminhos conceituais e exemplificatórios para compreender por que, em nossas situações de interação específicas na esfera acadêmica, lemos e escrevemos textosenunciados. Após essa discussão inicial, voltamo-nos às posições dos Estudos de Letramento, pois entendemos que ler textos-enunciados é uma prática social, histórica e cultural e, portanto, engendrada em eventos e práticas de letramento.

\section{LER TEXTOS-ENUNCIADOS: UM EVENTO SÓCIO-HISTÓRICO-CULTURAL E IDEOLÓGICO}

Situamo-nos, neste momento, em uma posição que considera a linguagem em uso em situações sociointeracionais e, portanto, responsável por instituir relações intersubjetivas. Consequentemente, nossa discussão em torno de ler e escrever textosenunciados na universidade adquire uma dimensão antropológica, política e social. A partir disso, evocamos os postulados dos Estudos de Letramento (BARTON; HAMILTON, 1998, 2000; GEE, 1996, 2000; HEATH, 1983; LANKSHEAR; KNOBEL, 2007, 2011; LEA; STREET, 2006).

Primeiramente, conforme esses postulados, entendemos que letramento corresponde a modos sociais de se utilizar a língua escrita em situações particulares de uso. O letramento em uma perspectiva social, histórica e cultural que encontra lugar nos Novos Estudos de Letramento concebe que a leitura e a escrita são sempre situados em práticas sociais específicas, instituindo relações sociais com valores singulares (GEE, 2000). Assim, ao interagir com o outro por meio da língua escrita, situamo-nos, ambos, 
em relações axiologicamente marcadas, possibilitando assumir ou não papéis sociais nas situações que se estabelecem. Pode-se avaliar um artigo a ser publicado em uma revista, assumindo-se o papel de parecerista. Ainda, pode-se assumir o papel de avaliador de uma tese, para conferir ou não o grau de doutor a um acadêmico, como, em outra ocasião, pode-se ser o acadêmico que, após a escrita da tese, espera a consequente (procedente) avaliação. Na universidade, como na vida social em geral, ao usar a língua, nas diferentes e múltiplas situações sociais, axiologicamente assume-se diferentes papéis.

Concordamos com Rodrigues e Cerutti-Rizzatti (2011), para quem o letramento diz respeito ao amplo fenômeno social de uso da escrita em diferentes espaços sociais, a fim de alcançar diferentes objetivos e instituindo diferentes relações intersubjetivas. Como reiteram as autoras, por letramento podemos compreender as práticas sociais que cada indivíduo assume em relação ao uso da língua escrita situada no contexto em que esse sujeito interage com outrem. Assim, ao escrever na universidade, estamos, dentre outras ações, instituindo relações sociais e nos posicionando em papéis específicos: aluno, acadêmico, pesquisador, profissional em formação, etc., que não apenas legitimam nossos textos-enunciados em situações particulares, como, por outro lado, os consubstanciam de sentido: por exemplo, a entrega de um relatório de estágio ao final do período do curso é requisito (parcial ou final) para o término da graduação e a obtenção do grau de graduado.

Dessa forma, ao endereçarmos nossa discussão nos Estudos de Letramento, estamos à procura de entender o que os homens fazem com a língua escrita nos espaços em que interagem (neste caso específico, nos espaços em que interagem na universidade) e que valores e relações de poder se legitimam nesses e por esses usos (BARTON; HAMILTON, 2000; GEE, 2000). Para tanto, inicialmente, retomamos as discussões em torno dos conceitos de modelos - autônomo e ideológico - aliados às concepções de eventos e práticas de letramento. Em segundo momento, revisitamos as pesquisas atuais em torno do Letramento Acadêmico e as considerações resultantes destes em torno da língua escrita na universidade. Acreditamos que, ao traçar esse caminho, estaremos não apenas vislumbrando ideias acerca da leitura e da escrita em contexto acadêmico, como, por conseguinte, arregimentando construtos sobre o que é ler e escrever em contextos múltiplos de uso da linguagem.

Por modelo autônomo de letramento, com base em Street (1984; 2003), entendemos a escrita desvinculada de seus contextos sociais de uso, caracterizada pela imanência e pela valorização de competências lógicas. Conforme explica Street (2003, p. 4), "o modelo [autônomo] disfarça as suposições culturais e ideológicas sobre as quais se baseia, que podem então ser apresentadas como se fossem neutras e universais [...]." Kleiman (1995, p. 22) explica que "a característica da autonomia refere-se ao fato de que a escrita seria, nesse modelo, um produto completo em si mesmo, que não estaria preso ao contex to de sua produção para ser interpretado [...]."

Assim, podemos entender que o modelo de letramento autônomo não apenas legitima uma concepção de língua escrita como habilidade lógica e tecnológica (STREET, 1984), como, em função disso, desvincula qualquer ancoragem social, histórica, cultural e ideológica do uso da linguagem. Rodrigues e Cerutti-Rizzatti (2011, 
p. 132) explicam que, sob a ótica desse modelo, a língua escrita seria considerada como uma "técnica", tendo como implicação habilitar indivíduos em domínios de uso da escrita, o que parece ser, segundo as autoras, o modelo que ancora muitas de nossas escolas (e, acrescentaríamos, universidades). Parece-nos que a discussão em torno do "déficit de letramento" que tem avançado no contexto universitário (e que vamos discutir a seguir) tem se pautado no modelo autônomo de letramento.

Em contrapartida ao modelo autônomo, Street (1984) propõe o conceito de modelo ideológico de letramento, que, dentre outras características, concebe o uso da língua escrita como uma prática sociocultural consociada a conjecturas de ordem ideológica e valorativa. Como explicam Rodrigues e Cerutti-Rizzatti (2011), esse modelo transcende a postura de entender a escrita como "técnica" e a entende como um fenômeno social, procurando compreender as formas plurais de como os indivíduos, em suas diversas situações de interação, se utilizam da língua escrita, não apenas instituindo-se enquanto sujeitos, como, por conseguinte, assumindo posições e legitimando relações intersubjetivas de ordem heterogênea (hierarquizada, ou não, por exemplo). O modelo ideológico, como o próprio conceito já pressupõe, vincula letramento aos usos socioideológicos da língua escrita em espaços contextuais pluridiversificados.

Conforme explica Street (2003, p. 4), “o modelo ideológico [...] oferece uma visão com maior sensibilidade cultural das práticas de letramento, na medida em que elas variam de um contexto para outro." E ainda reitera, "esse modelo parte de premissas diferentes adotadas pelo modelo autônomo - propondo por outro lado que o letramento é uma prática de cunho social [...]." (p. 4). Assim, o modelo ideológico nos situa em uma rota que procura entender que, ao usar a língua escrita no contexto da universidade, estamos, dentre outras questões, nos situando em práticas sociais de uso da escrita particulares, coconstruindo, em trabalho intersubjetivo com o outro, sentidos particulares, engendrados em projeções ideológicas (e valorativas) singulares e posições sociais identitárias consociadas a essa situação interativa particular. Compreendemos, portanto, que participar de espaços interacionais de uso da língua escrita na universidade é assumir papéis sociais dos quais e a partir dos quais coconstruimos sentidos para esse uso. Além disso, como lembram Rodrigues e Cerutti-Rizzatti (2011), os dois modelos não instituem uma polarização, mas, há, conforme explica Street (2003), uma imbricação entre eles. Segundo o autor,

[...] os modelos jamais foram propostos como opostos polares: em vez disso, o modelo ideológico de letramento envolve o modelo autônomo. A apresentação do letramento como sendo "autônomo" é apenas uma das estratégias ideológicas empregadas em associação ao trabalho no campo do letramento, que em realidade disfarça a maneira em que a abordagem supostamente neutra efetivamente privilegia as práticas de letramento de grupos específicos de pessoas. Nesse sentido, o modelo autônomo mostra-se profundamente ideológico. Ao mesmo tempo, o modelo ideológico consegue perceber as habilidades técnicas envolvidas, por exemplo, na decodificação, no reconhecimento das relações entre fonemas e grafemas e no engajamento nas estratégias aos níveis de palavras, sentenças e textos [...]. Entretanto, o modelo ideológico reconhece que essas habilidades técnicas estão sempre sendo empregadas em um contexto social e ideológico, que dá significado às próprias palavras, sentenças e textos com os quais o aprendiz se vê envolvido. (STREET, 2003, p. 9, grifos do autor). 
Assim, o modelo autônomo de letramento diz respeito a uma visão ainda descontextualizada do uso da língua escrita, ao passo que, o modelo ideológico, por outro lado, corresponde a entender a língua escrita em entornos sócio-histórico-culturais de uso.

Dada nossa compreensão dos modelos, tomamos os conceitos de eventos e práticas de letramento, o que nos parece ser também essencial para nosso entendimento em torno do que seja ler e escrever na universidade. Se, como já dito, concebemos a leitura e a escrita como práticas sociais, compreendemos também que ler e escrever se imbricam em eventos e práticas de letramento.

Eventos de letramento, segundo estudos de Heath (1983), correspondem a qualquer situação interativa em que a língua escrita faça parte da natureza dessa interação e, por conseguinte, da construção de sentido. Assim, ler um artigo científico na universidade, ou escrever um resumo informativo para a aula de uma determinada disciplina, como tarefa extracurricular, são exemplos de eventos de letramento na esfera acadêmica. Em nossa vida diária, não apenas na universidade, coparticipamos de diferentes eventos de letramento, tais como ler um jornal em busca de estágio extracurricular ou para saber o horário de um filme no cinema; ir ao caixa eletrônico realizar uma transferência bancária; ou ainda escrever um e-mail a um colega solicitando informações sobre a aula que se perdeu. Os exemplos caracterizam-se por estarmos em situações particulares de interação, nos utilizando de gêneros do discurso escritos diversos para atingir fins determinados. Assim, toda vez que interagimos em situações mediadas pela língua escrita, nós coparticipamos de eventos de letramento. $\mathrm{E}$ na universidade são vários e multiformes os eventos de letramento e os gêneros do discurso que medeiam esses eventos, como:

\section{Quadro 4 - Eventos de letramento e gêneros do discurso}

\begin{tabular}{|l|c|}
\hline Evento de letramento & Gênero do discurso \\
\hline $\begin{array}{l}\text { Sintetizar as ideias de um livro de uma disciplina } \\
\text { para a realização de uma prova. }\end{array}$ & Resumo informativo \\
\hline $\begin{array}{l}\text { Sintetizar as informaçoes teórico-metodológicas de } \\
\text { um projeto de pesquisa para realizar a inscrição em } \\
\text { um evento acadêmico. }\end{array}$ & Resumo indicativo \\
\hline $\begin{array}{l}\text { Descrever, analisar, avaliar e (não) recomendar } \\
\text { uma obra recém-publicada na área. }\end{array}$ & Resenha \\
\hline $\begin{array}{l}\text { Esboçar as principais ideias de uma apresentação } \\
\text { oral com base na pesquisa em desenvolvimento. }\end{array}$ & Handout \\
\hline
\end{tabular}

Fonte: Discussão dos autores

Com base no quadro acima, podemos entender que todos os eventos de letramento são sempre mediados por gêneros do discurso, pois estes não apenas significam nossas situações interativas, como também, por meio deles, instituímos relações interpessoais, como vimos na seção anterior. Outra questão pertinente é que os eventos de letramento 
sempre se realizam para determinados fins, isto é, sujeitos se utilizam da escrita para alcançar determinados objetivos, como vimos no quadro acima: escrevemos um resumo indicativo, por exemplo, porque estamos propondo uma comunicação oral em um evento; escrevemos uma resenha porque estamos avaliando uma obra em nossa área. A partir disso, podemos conceber eventos de letramento como situações de interação, mediadas por gêneros do discurso específicos da esfera da qual as situações se engendram, nas quais os sujeitos se utilizam da língua escrita para determinados fins.

Para explicar questões de ordem subjacente aos eventos de letramento, Street (2003, p. 8) postula o conceito de práticas de letramento, que, segundo o autor, "[...] referem-se a esse conceito cultural mais amplo das formas específicas de pensar e de fazer a leitura e a escrita dentro de contextos culturais." Dessa forma, as práticas correspondem aos construtos sociais, culturais, históricos, ideológicos e valorativos que se imbricam nos eventos de letramento.

Se pensarmos nos eventos de letramento citados em nosso quadro acima, as práticas seriam as conjecturas sobre as quais realizamos o uso da língua dados como exemplos: se participar de eventos acadêmicos parece ser importante na formação acadêmico-profissional de um estudante de graduação, é porque determinadas conjecturas de ordem histórico-cultural e ideológico-valorativas instituem essa importância no contexto universitário. Se publicar resenhas parece ser importante na área de Letras, em que se sedimenta uma cultura de publicação de livros como formas de socialização do conhecimento, na área de Física tal prática de letramento pode não se realizar, como vimos no início deste ensaio. Com isso, as práticas de letramento se configuram como conjecturas sociais, históricas, culturais, ideológicas e valorativas que se imbricam e, em confluência, consociam-se aos eventos de letramento, significandoos e legitimando-os em situações de interação particulares de uso da língua escrita.

Enquanto os eventos são fotografáveis, as práticas são apenas apreendidas a partir da análise dos eventos. É nas práticas que se assentam as bases dos eventos de letramento (BARTON; HAMILTON, 2000). Conscientizar-se, portanto, sobre modelos, eventos e práticas de letramento e associá-las ao entendimento de que, nas diferentes situações sociais, interagimos por meio de gêneros do discurso, nos conduz a, nessa parte final do ensaio, nos situarmos contrários aos dizeres em torno do déficit de letramento que têm se instaurado nos mais diversos contextos universitários. Os discursos inflamados acerca do não saber ler e escrever parecem ter tomado conta das explicações (superficiais) sobre a leitura e a escrita de universitários, ainda mais em tempos de diversas políticas públicas de acesso ao ensino superior.

“Os alunos, em plena universidade, não sabem ler nem escrever!” Quem ainda não ouviu essa exclamação logo participará de alguma discussão na qual seja esse o argumento explicativo. A voz (sedimentada e, por vezes, legitimada por diferentes instituições, dentre muitas, a própria universidade) do déficit de letramento, que rotula os acadêmicos ingressantes (ou não) na universidade como incompetentes para ler e escrever, parece estar ecoando de forma ressonante. Cotidianamente, na voz de diversos docentes universitários, a posição axiológica da crise faz-se presente. Como afirma Fischer (2007, p. 16), 
[Os] professores alegam a restrita ou difícil participação dos alunos em atividades que exigem leitura, produção escrita e oral de textos. Este dado impossibilitava o avanço do conteúdo proposto a ser trabalhado nos semestres letivos dos cursos de graduação. Os alunos, por sua vez, indicavam o quanto era difícil e árduo o trabalho proposto pelos professores, por não terem conhecimento suficiente dos assuntos, dos gêneros discursivos solicitados para leitura, escrita, etc. Ficava instaurada uma situação de antagonismos, em que professores e alunos não interagiam satisfatoriamente para a construção de conhecimentos, envolvendo a leitura e a produção de textos.

Como percebemos, na voz de Fischer (2007), as afirmativas de professores e alunos indicam que há conflitos que se instauram em torno do que se espera dos alunos no ensino superior: não apenas um conflito de identidade (GEE, 1999), como um conflito de abordagem. Um conflito de identidade porque na universidade parece haver um consenso (falso) de que o acadêmico, após anos de Educação Básica, ingressa no Ensino Superior proficiente em leitura e escrita e, portanto, desde o primeiro dia de aula, insider (GEE, 2001) da esfera acadêmica; um conflito de abordagem, porque os professores, em sua maioria, sedimentam e legitimam esse consenso, e a aula não passa de um "acontecimento encenado": encena-se que se lê e encena-se que se escreve ${ }^{5}$, ao final, tudo termina com um belo final (in)feliz.

Sob essa perspectiva, o que procuramos, ao final de nosso ensaio, é ratificar o compromisso da ausculta, enquanto professores, das considerações teóricoepistemológicas trazidas dos escritos do Círculo de Bakhtin e dos Estudos de Letramento para, em um diálogo enquanto ação (PONZIO, 2012), arregimentarmos considerações que ressignifiquem o ensino da leitura e da escrita na universidade, evitando o enraizamento de consensos falsos, desleixados e cênicos, para ações concretas, comprometidas e empoderadas (FREIRE, 1972). A fim de que possamos (re)pensar e modificar nossas ações e que nossa atuação em sala se transforme em um fazer sócio-histórico, cultural, ideológico e compromissado. Acreditamos nesse caminho.

\section{CONSIDERAÇÕES FINAIS}

Neste ensaio chamamos a atenção para a importância do estudo dos gêneros do discurso no sentido de perceber como se dão as práticas engendradas em eventos de letramento na esfera acadêmica, tanto no que diz respeito ao reconhecimento dos gêneros que circulam nesse campo, quanto às situações de uso, uma vez que os gêneros tomados como unidades discursivas regulam, organizam e se constituem em formas (relativamente estáveis) de interação humana. Assim, como pontuam Bakhtin [Volochínov] (2006 [1929], p 127),

A verdadeira substância da língua não é constituída por um sistema abstrato de formas linguísticas, nem pela enunciação monológica isolada, nem pelo ato psicofisiológico de sua produção, mas pelo fenômeno social da interação verbal, realizada através da enunciação ou das enunciações. A interação verbal constitui assim a realidade fundamental da língua.

\footnotetext{
${ }^{5}$ À luz de Werneck (1992).
} 
Além disso, ao longo do presente ensaio, discutimos a produção escrita e a leitura, no contexto da universidade, numa perspectiva do letramento, na medida em que compreendemos que, enquanto unidades discursivas, os gêneros medeiam eventos de letramento. Desse modo, parece-nos profícuo relacionar esses eventos ao contexto de sua emergência, em que vozes se sobrepõem e se opõem em processos de coconstrução e circulação de conhecimento.

Compreendemos o termo 'letramento' como um fenômeno sempre socialmente situado e condicionado por aspectos socioeconômicos, históricos, culturais, políticos e educacionais. O letramento acadêmico diz respeito ao uso de linguagens especializadas nesse contexto. E faz referência aos papéis sociais desejáveis de alunos e professores no que diz respeito às relações estabelecidas com o conhecimento e com o saber. Todos esses aspectos inter-relacionam-se inevitavelmente, pois o letramento, compreendido como um fenômeno sócio-histórico-cultural, envolve (GEE, 1999, 2001) formas de ser, falar, ouvir, escrever, ler, agir, interagir, acreditar, valorizar, sentir, usar recursos, ferramentas, tecnologias, aspectos que devem ser considerados pelo professor na universidade.

Assim, considerando que o letramento constitui-se como modos sociais e culturais de uso da língua escrita, implica estudar a sala de aula como um lugar social e cultural em que práticas particulares de ler e escrever podem servir na ação de questionar quais textos, formas de falar, ler, escrever e comportar-se são privilegiados e por quê.

\section{REFERÊNCIAS}

ACOSTA-PEREIRA, R. O gênero carta de conselhos em revistas online: na fronteira entre o entretenimento e a autoajuda. 2012. 259f. Tese (Doutorado em Linguística) - Programa de Pós-graduação em Linguística, Universidade Federal de Santa Catarina, Florianópolis, 2012.

. O gênero jornalístico notícia: dialogismo e valoração. 2008. 229f. Dissertação (Mestrado em

Linguística) - Programa de Pós-graduação em Linguística, Universidade Federal de Santa Catarina, Florianópolis, 2008.

ADAM, J. M. Eléments de linguistique textuelle. Liège: Madarga, 1990.

Les textes: types et prototypes. Paris: Nathan, 1992.

BAKHTIN, M. M. Estética da criação verbal. Tradução do russo por Paulo Bezerra. 4. ed. São Paulo: Martins Fontes, 2003 [1979].

; [VOLOCHÍNOV, V. N]. Marxismo e filosofia da linguagem: Problemas fundamentais do método sociológico na ciência da linguagem. Tradução do francês por Michel Lahud e Yara F.Vieira. $12^{\circ}$ ed. São Paulo: Hucitec, 2006 [1929].

Problemas da poética de Dostoiévski. Tradução do russo, notas e prefácio de Paulo Bezerra. 4. ed. Rio de Janeiro: Forense Universitária, 2008 [1963].

BARTON, D. Literacy: an introduction to the ecology of written language. Cambridge, USA: Brackwell, 2004.

BARTON, D.; HAMILTON, M. Literacy practices. In: BARTON, D.; HAMILTON, M.; IVANIC, R. (Eds.). Situated Literacies: Reading and writing in context. London: Routledge, 2000, p. 7 - 15.

Local literacies: Reading and writing in one community. London: Routledge, 1998.

BENVENISTE, E. Problèmes de linguistique générale I. Paris: Gallimard, 1966.

DUCROT, O. O dizer e o dito. Campinas: Pontes, 1987. 
GEE, J.P. Reading as situated language: a sociocognitive perspective. Journal of adolescent \& adult literacy, v. 8, n. 44, p. 714-725, 2001.

The New Literacy Studies: from "socially situated" to the work of the social. In: BARTON, D; HAMILTON, M.; IVANIC, R. (Eds.). Situated literacies: Reading and writing in context. London: Routledge, 2000a. p. 180-196. Press, 1999.

Social linguistics and literacies. Ideology in Discourses. 2.ed. London/Philadelphia: The Farmer

Social linguistics and literacies: ideology in discourses. London: Farmer, 1996.

FISCHER, A. A construção de letramentos na esfera acadêmica. 2007. 340f. Tese (Doutorado em Linguística) - Programa de Pós-graduação em Linguística, Universidade Federal de Santa Catarina, Florianópolis, 2007.

FREIRE, P. Pedagogy of the Oppressed, Harmondsworth: Penguin, 1972.

HEATH, S. B. Ways with words: Language, life, and work in communities and classrooms. Cambridge: Cambridge University Press, 1983.

KLEIMAN, A. Os significados do letramento. Campinas: Mercado das Letras, 1995.

LANKSHEAR, C.; KNOBEL, M. New literacies. New York: Open University Press, 2011.

(Org.). A new literacy sampler. New York, Peter Lang, 2007. 252 p.

LEA, M.R.; STREET, B.V. The “Academic Literacies" Model: theory and Application. Theory into Practice, v. 45, n. 4, p. 368-377, 2006.

Student writing in higher education: an academic literacies approach. Studies in Higher Education. London, v. 23, n. 2, p. 157-172, June 1998.

MEDVEDEV, P. N. O método formal nos estudos literários: introdução crítica a uma poética sociológica. Tradução do russo por Ekaterina Américo e Sheila Grillo. São Paulo: Contexto, 2012 [1928]. MOTTA-ROTH; D; HENDGES, G. H. Produção textual na universidade. São Paulo: Párabola, 2010. PONZIO, A. Dialogando sobre diálogo na perspectiva bakhtiniana. São Carlos: Pedro \& João Editores, 2012.

RODRIGUES. R. H. Os Gêneros do Discurso na Perspectiva Dialógica da Linguagem: A Abordagem de Bakhtin. In: MEURER, J. L; BONINI, A; MOTTA-ROTH, D. Gêneros: teorias, métodos e debates. São Paulo: Parábola, 2005. p. 152-183.

RODRIGUES; R. H; CERUTTI-RIZZATTI, M. Linguística Aplicada: ensino de língua materna. Florianópolis: LLV-CCE-UFSC, 2011.

STREET, B.V. What's new in New Literacy Studies? Critical approaches to literacy in theory and practice. Current Issues in Comparative Education, New York, v. 5, n. 2, p. 77-91, 2003.

Literacy in theory and practice. Cambridge: Cambridge University Press, 1984.

WERNECK, H. Se você finge que ensina, eu finjo que aprendo. Petropólis/RJ: Ed. Vozes, 1992.

Recebido em: 16/10/14. Aprovado em: 20/04/15.

Title: Reading and learning in the University: a social, historical and cultural practice Authors: Rodrigo Acosta Pereira; Sandro Braga

Abstract: The present essay aims at delineating a theoretical and methodological discussion about the reading and writing teaching and learning practices in academic sphere based on social and historical epistemological considerations. To do so, we review Bakhtin's Circle and New Literacies studies in order to construct a debate concerning the use of written language in the university. We believe that this essay is relevant not only because it seeks to contribute with the Applied Linguistics current discussions about reading and learning in the academic sphere as well as it corroborates the contributions of bakhtinian studies and the researches of academic literacy to the reframing of pedagogical practices around the reading and writing teaching at the university.

Keywords: Reading. Writing. Academic sphere. Discourse genre. Literacy(ies). 
Título: Leer y escribir en la universidad: un hacer socio-histórico-cultural

Autores: Rodrigo Acosta Pereira; Sandro Braga

Resumen: El presente artículo tiene por objetivo delinear una discusión teóricometodológica acerca de las prácticas de enseñanza y de aprendizaje de lectura y escrita en la esfera académica, bajo la luz de las consideraciones epistemológicas de naturaleza socio-histórica. Para ello, revisitamos escritos del Círculo de Bajtín, también las postulaciones de los Nuevos Estudios de Alfabetismo para construir inteligibilidades alrededor de las prácticas de uso de la lengua escrita en la universidad. Creemos que el trabajo se presenta relevante no solo porque, bajo nuestra mirada, procura contribuir con las discusiones actuales de la Lingüistica Aplicada sobre las prácticas de escrita y lectura en la academia, también porque corrobora las contribuciones de los estudios de Bajtín y las investigaciones sobre alfabetismo académico para una nueva significación del hacer pedagógico alrededor de la enseñanza y de la aprendizaje de la lectura y de la escrita en la universidad.

Palabras-clave: Lectura. Escrita. Esfera académica. Género del discurso. Alfabetismo(s). 